\title{
Epigenetic synthesis: a need for a new paradigm for evolution in a contaminated world David Crews ${ }^{1,3 *}$ and Andrea C. Gore ${ }^{2,3}$
}

\begin{abstract}
Addresses: ${ }^{1}$ Section of Integrative Biology, The University of Texas at Austin, Austin, TX 78712, USA; ${ }^{2}$ Division of Pharmacology \& Toxicology, The University of Texas at Austin, Austin, TX 78712, USA; ${ }^{3}$ Institute for Cellular and Molecular Biology, The University of Texas at Austin, Austin, TX 78712, USA

* Corresponding author: David Crews (crews@mail.utexas.edu)

FI000 Biology Reports 2012, 4:18 (doi:I0.34I0/B4-I8)

This is an open-access article distributed under the terms of the Creative Commons Attribution-Non Commercial License (http://creativecommons.org/licenses/by-nc/3.0/legalcode), which permits unrestricted use, distribution, and reproduction in any medium, provided the original work is properly cited. You may not use this work for commercial purposes.

The electronic version of this article is the complete one and can be found at: http://fl000.com/reports/b/4//8

Abstract

Epigenetics is a perspective, not a set of techniques. Molecular biology and genetics are the dominant disciplines in biology today, but practitioners of these fields have only recently 'rediscovered' the importance of the environment. This has led to increasing research into molecular epigenetics and the interface between the environment and gene regulation. Beyond the study of epigenetic mechanisms at the level of the gene, more investigation of epigenetic outcomes at the level of both the individual organism and the evolution of the population is needed.
\end{abstract}

\section{Introduction}

The advent of the chemical revolution 70 years ago resulted in the synthesis of over 80,000 man-made chemicals, a fraction of which have made their way into the environment and now pose a serious risk to both wildlife and human health [1]. A subset of these chemicals are 'endocrinedisrupting chemicals', defined in a recent Statement of Principles from The Endocrine Society as: "an exogenous chemical, or mixture of chemicals, that interferes with any aspect of hormone action" [2]. Even exceptionally low levels of endocrine-disrupting chemicals can be biologically relevant, especially if exposure occurs at an age when there is normally little endogenous hormone action [3]. It is widely accepted that endocrine-disrupting chemicals can induce molecular epigenetic changes, such as DNA methylation and histone modification [4]. Until very recently, however, species evolved in the absence of anthropogenic endocrine-disrupting chemicals, so the long-term evolutionary consequences of this remain to be seen. Epigenetics is the next epoch in evolutionary theory, as these mechanisms alter heritability and force us to confront classical genetic ways of viewing the environment.

There is no question that the world is contaminated $[5,6]$, never to return to conditions that existed prior to the industrial and chemical revolutions. Although some local remediation of contamination has occurred, at a global level this is simply not possible. From the evolutionary perspective, it is evident that organisms can adapt to contamination [7] and that 'cleaning up' the environment represents further environmental stress, forcing further changes. It is possible, and desirable, to slow the rate and nature of contamination by regulating better-known endocrine-disrupting chemicals. We also advocate developing green chemistry methods to synthesize chemicals that are not "hazardous for human health and the environment", so as not to add to the burden of contamination [8]. Now that these compounds are a permanent part of our environment, it is imperative that we develop new methods and perspectives if we are to anticipate and understand their impact on our future.

\section{Evolution and Gene X Environment studies}

Evolutionary theory accounts for the process of change in life forms. It has had two epochs, with a third emerging. The first, Darwinian evolution, established the principle of change through selection. The second, the Modern Synthesis [9-12], provided the units of heredity and their control, particularly change in DNA by recombination and mutation. We are entering the third epoch, what we 
might call the Epigenetic Synthesis, which combines elements of the previous iterations and incorporates environmental modulation of temporal and spatial control of gene expression without altering the underlying DNA sequence.

Traditionally, evolutionary studies have focused on studying living organisms to reconstruct past history. Phylogenetic studies accomplish this by comparing extant species, while paleontological studies unearth deep history. A recent strategy reconstructs ancient traits and molecules of evolutionary progenitors to recreate those processes $[13,14]$. What this and other research has taught us is that there is remarkable conservation in the genetic code that links all animals.

With the focus on genetics came the belief that evolution required fundamental changes to the unit(s) of heredity; the discovery of the structure of DNA gave credence to the idea that the genes themselves were the bricks from which the phenotype was built. This was reified in the paradigm of Gene X Environment (G X E) and its modern variants, such as genome-wide association studies (GWAS), quantitative trait nucleotides (QTNs), and whole-genome sequencing. This perspective holds that phenotypes, including disease, must have a genetic basis. However, much research shows that although there are monogenic diseases, these are rare and the genetic contribution to most diseases is only about $2-5 \%$, and also that multiple genes are involved in nearly every trait/disease $[15,16]$. Even in monozygotic twins, a benchmark for assessing genetic risk in non-Mendelian disease, discordance is significant ( $85 \%$ for breast cancer, $55-75 \%$ for diabetes, $50 \%$ for schizophrenia, $70 \%$ for bipolar disorder) [17-20], making genetic testing relatively uninformative for most diseases $[21,22]$. Thus, the idea that genes determine traits is more proof by conviction than proof by substance. In fact, we now know that genetics is a subordinate player in virtually everything except for pathological situations, such as cancers. The conclusion we must face is that, in most situations, it is how the genome is regulated, not the nucleotide sequence itself that is important.

The Mendelian geneticists effectively overthrew the Darwinian naturalists who emphasized the importance of the environment in shaping the phenotype. Modern molecular biologists have learned it was a mistake to ignore the environment as an important variable. Should the favor be returned and have us throw out genetics in favor of epigenetics? We do not suggest this, but we resist the opinion that there must be genetic predispositions to flexibility or plasticity. We must resist the urge to shoehorn epigenetic concepts into established dogma. Like buying shoes for a growing child, the fit is usually unsatisfactory but often accepted, leading to future foot problems. Indeed, classical and population geneticists have particular problems with the shifting sands of this new science [23-25]. This is particularly evident from the number of papers that have in their title or text epigenetics interpreted within a G X E context. It is time to think outside the box and develop de novo principles and practices to better predict what the future holds. Thus, the new revolution should be firmly rooted in epigenetics.

\section{The Epigenetic Synthesis}

When defined broadly, epigenetics provides a very different perspective. It emphasizes how environmental experiences (whether internal or external, biotic or abiotic) modify the molecular factors and processes around DNA to regulate genome activity independent of the DNA sequence, essentially establishing an "imprint" that provides temporal and spatial control of genomic activity. The functional consequences of molecular epigenetic changes are that the organism responds differently to its environment.

There is a long history in evolutionary biology and psychology that laid the groundwork for the discovery and appreciation of epigenetics that must be understood if its potential is to be realized. First, though, it is important to distinguish the mechanisms underlying the epigenetic process and to go beyond the current emphasis on molecular processes (e.g. DNA methylation, histone modifications, long-noncoding RNAs, etc.). For the purpose of this essay, we can think of two major categories of change as Epigenetic context-dependent $\left(\mathrm{E}_{\mathrm{c}}\right)$ versus Epigenetic germline-dependent $\left(\mathrm{E}_{\mathrm{g}}\right)$ modifications. The former are caused by exposure to environmental factors, including endocrinedisrupting chemicals, social/behavioral factors, or other conditions. So long as the causal agent bringing about the epigenetic modification persists, the epigenetic modification will manifest in each generation. Removal of the causative agent or addition of a different environmental factor (e.g. diet supplementation) can remediate the modification. In contrast, germline-dependent epigenetic modifications occur when the epigenome is permanently imprinted and, hence, will manifest in each generation in the absence of the causative factor. Both context- and germline-dependent epigenetic modifications have generational properties, for example passing from either parent to the young, but only germline-dependent modification is truly transgenerational inheritance, because it is in the germline and does not require further exposure to environmental stimuli to be manifested.

The Epigenetic Synthesis focuses on the interaction between germline-dependent $\left(\mathrm{E}_{\mathrm{g}}\right)$ and context-dependent $\left(E_{c}\right)$ modifications. That is, rather than G X E or GWAS, it is $E_{g} X E_{c}$ that explains most of the variance observed. 
Figure I. The Epigenetic Synthesis

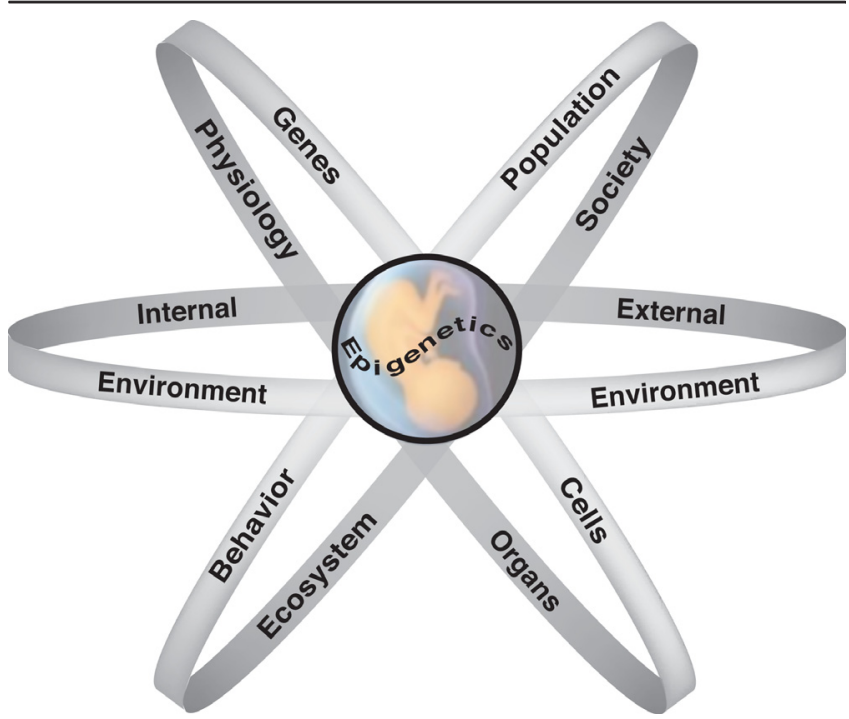

The external environment interacts with the internal environment to influence fetal development with both immediate and life-long consequences. Such environmentally-induced changes occur at all levels of biological organization, from the molecular to the organism's behavior, and tend to be amplified in their consequences as they ascend through these levels. Ultimately, these influences may be epigenetic in nature, inducing mitotically heritable alterations in gene expression without changing the DNA. Changes can occur at the neural, physiological, and morphological levels (Molar Epigenetics) as well as modification of normal patterns of gene expression (Molecular Epigenetics). These alterations can bring about functional differences in behavior that result in changes in how the individual responds to conspecifics and their environment, bringing about changes at the population and higher levels of biological organization. Human society has changed the ecosystem in a manner that has had demonstrable impact on the health of humans and wildlife and, hence, changed the evolutionary trajectory.

Beyond additivity or synergism, of greatest importance is the emergent property of the interaction: that is, how transgenerational germline-dependent modifications alter the organism such that it responds to proximate stimuli, such as context- dependent environmental stressors, in a different manner [26] (Figure 1). In other words, in this paradigm the germline genome view of traditional genetics (the G of the G X E paradigm) is not the main factor, but rather how the genome is regulated that is the nexus. This is particularly true for humans, who are relatively recently evolved beings. Here, it is their 'shallow' (generations or heritage), rather than the 'deep' (millions of years or phylogeny), ancestry in the genetic sense that is important.

\section{Evolution, epigenetics, and endocrine-disrupting chemicals}

Why is it necessary to develop a new paradigm? Evolution is the fabric of time with reproductive success
Figure 2. The evolution of new species in a contaminated world

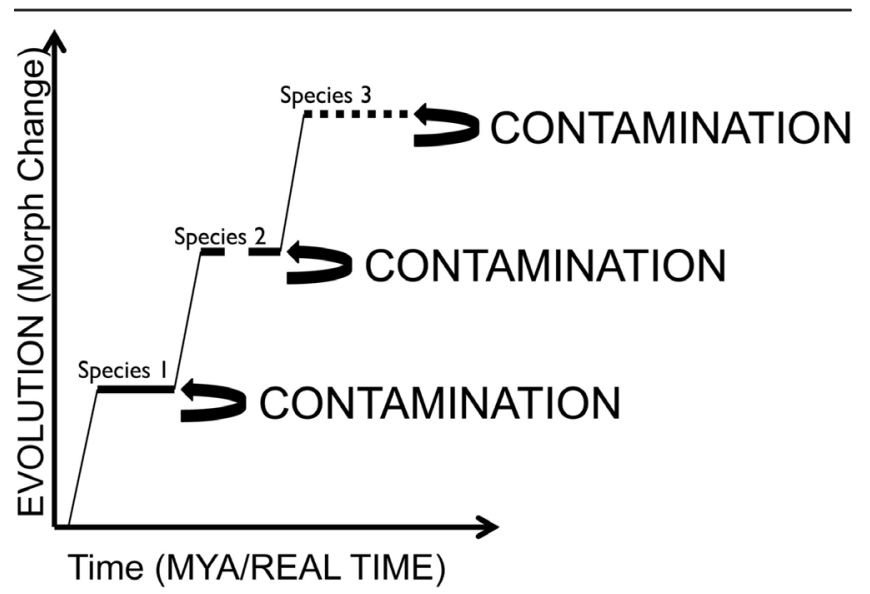

The theory of punctuated evolution was developed to account for the abrupt transitions in the fossil record; it can be applied to present day conditions of environmental contamination, particularly in instances of localized spills. In both Darwinian evolution and industrial accidents, the predicted change versus the observed change in phenotype/clades differs. Evolution is not a gradual and incremental process (indicated by sloped line) with species changing gradually into new forms (gradualism). Rather, it is abrupt (indicated by steps), with formation of new species during periods of rapidly changing environmental conditions interspersed with periods of stability. Endocrine disrupting compounds alter the brain and behavior of exposed individuals and potentially that of their descendants, hence, leading to similar conditions of incipient speciation.

its warp and individual differences its weave. Change is marked by the advent, maintenance, and eventually the extinction of species. A case in point is the fossil record, a mosaic (fractured picture) of time past. Darwinian evolutionary theory predicted uniform but incremental (slow) change mediated by selection. However, the lack of such evidence of graded intermediate steps and, instead, the abrupt transition of forms in the fossil record, led to the theory of punctuated equilibria put forth by Eldredge and Gould [27], anticipated decades earlier by Ablowitz [28]. They noted that transformative periods might mark periods of explosive change at both the species level as well as at the level of larger groups or clades interspersed by prolonged periods of stasis with little or no change. Instrumental to the punctuated equilibrium theory was Richard Goldschmidt's macromutations or 'hopeful monster' hypothesis, in which the rare phenotype, so unlike any other extant at the time, succeeds and paves the way for such transformative events [29]. We contend that environmental contamination by endocrine-disrupting chemicals has created the conditions of incipient speciation. The world has been fundamentally transformed in the past 5 decades - a paleontological blink of an eye - consistent with the upward trajectory of punctuated equilibrium (Figure 2). 
An epigenetic basis for this rapid transformation of form involving the silencing of transposable elements by environmental stressors has been proposed [30]. Thus, we suggest that endocrine-disrupting chemicals are a major category of environmental stressors that have created monsters 'hopeful' to find mates. As this paper was going to press, we learned of a remarkable series of studies [31-33] using lab mice genetically modified to have a dysfunctional Per gene (the gene coding for circadian rhythmicity) but placed in outdoor enclosures and, hence, undergoing natural and sexual selection. These studies concluded that mice underwent epigenetic compensation for an adverse genetic trait.

In the Modern Synthesis, species formation was believed to result only after geographic separation and isolation of parts of the population, but it is now recognized that new species can arise in situ (i.e. sympatric speciation), e.g. changes in host-plant selection in apple maggots and 'resident' and transient forms of killer whales in the northeast Pacific. The controversy regarding these modes of speciation continues, but there has been a shift in evolutionary biology away from the isolationist perspective toward understanding the mechanisms that enable divergence of species in areas of sympatry [34,35]. This has led to a reconsideration of the importance of interbreeding as an essential component of the 'biological species concept' as many species can be made to interbreed under forced or artificial conditions when they would otherwise, given free choice, avoid doing so.

While it is in an individual's best interest to avoid mating with a divergent species (resulting in no offspring or infertile offspring), it is more important to select (through mutual agreement) the best mate within its own species, as happens in nature [35], thereby optimizing reproductive success. Further, the behavioral components of mating themselves are part of the complex process leading to successful reproduction. In vertebrates, the male's courtship and insemination induce behavioral and physiological responses in the female that may increase her receptivity, change her hormones, affect the probability of ovulation, and ultimately enhance the likelihood that his sperm will fertilize her eggs. Thus, both the physiological and behavioral components of mating are vulnerable to environmental endocrine-disrupting chemicals. There is abundant evidence for perturbation of reproduction by endocrine-disrupting chemicals, beginning with Rachel Carson's Silent Spring [36] discussing the consequences of pesticides, such as DDT in wildlife. What is not as commonly appreciated is the effects of endocrinedisrupting chemicals on the behavioral aspects of reproduction, as well as other non-reproductive behaviors, in shaping evolutionary change.

\section{Endocrine-disrupting chemicals, brain and behavior - evolutionary consequences}

Behavior is the leading edge of evolutionary change [37]. That is, it is how the animal responds to its environment, including other individuals, that is the functional unit of selection. The brain, the organ of behavior, is one of the most important targets of endocrine-disrupting chemicals and we must consider their consequences on the intersection of brain, behavior, and the evolutionary process. There is clear evidence that, in some instances, contamination compromises the reproductive capacity of individuals and they cannot breed. There are many examples of such "monsters": feminized fish, multilimbed frogs, infants undergoing puberty. But it is also evident that reproduction continues in contaminated areas [38]. Even if both sexes are compromised, they may encounter unaffected, as well as affected individuals, during the breeding season. Should affected individuals choose to mate with affected members of the same species, there may be no evolutionary impact if they are sub- or in-fertile. However, if there were an asymmetry in mate preference (e.g. affected males mating with unaffected females or vice versa) then the impact on the population would be significant, particularly if germline modifications caused by endocrine-disrupting chemicals are propagated. Until recently there have been few studies evaluating whether an individual's attractiveness as a mate, or in turn one's own perception of suitable mates, are modified by their progenitors' exposure to environmental contaminants. For example, starlings foraging in the winter on worms in sewage-effluent filter beds receive significantly higher amounts of synthetic and natural estrogens and other endocrine-disrupting chemicals than starlings foraging on worms found in garden soil [39]. During the winter, captive male starlings were fed mealworms containing ecologically relevant levels of a mixture of endocrine-disrupting chemicals found in worms in contaminated sites. The amount and complexity of song, and the size of each bird's higher vocal center (HVC) was assessed the following spring. Male song and brain HVC volume were increased in individuals receiving the mixture; these males also showed significantly lower immune function. Females preferred the more complex song of males that had received the endocrinedisrupting chemical mixture. Thus, by selecting males with more complex song, the females were also selecting males who were immunocompromised.

A second example is that of exposure to the fungicide and endocrine disruptor vinclozolin, during the period of embryonic sex determination and gonadal differentiation in rats. This results in an acceleration of late-onset adult diseases, the phenotype of which is expressed by subsequent unexposed male progeny for 3 generations. 
Importantly, this phenotype is associated with DNA methylation changes in the sperm - a clear example of context-dependent changes [40]. In addition, such epigenetic modifications change the behavior and brain transcriptome [41] and mate preference behavior [42]. Recently, Stouder et al. also showed effects of vinclozolin on methylation of imprinted genes [43]. Other endocrine-disrupting chemicals (bisphenol A, PCBs, and diethylstilbestrol) also have transgenerational epigenetic effects (reviewed in [4]).

Real life, however, is a combination of germline- and context-dependent epigenetic modifications. To our knowledge, this has been experimentally confirmed in animals for the first time in a model of transgenerational epigenetic modifications caused by ancestral vinclozolin exposure, with the unexposed descendants (F3 generation) subjected to a stressful environment in adolescence. We showed that germline-dependent epigenetic modifications alter the brain, transcriptome, physiology, behavior, and metabolic activity in discrete brain nuclei in these descendants, and, importantly, the individuals respond very differently to their immediate environment in terms of context-dependent epigenetic modifications [44]. Thus, germline- and context-dependent epigenetic modifications together can transform the essential elements of the phenotype. When applied to the real life examples of contamination, such animals should be considered, until proven otherwise, as potential founder populations of new species. In other words, selection may act to modify how a contaminant alters the epigenome [45].

\section{Conclusion}

Only when molecular biology and genetics incorporate the deep history and perspective of other disciplines, such as evolutionary biology, evo-devo, behavioral ecology, ethology and psychology will the potential of epigenetics be realized $[45,46]$. We suggest that an Epigenetic Synthesis $\left(\mathrm{E}_{\mathrm{g}} \mathrm{X} \mathrm{E}_{\mathrm{c}}\right)$ combines elements of classical Darwinian theory, together with the Modern Synthesis, and extends it to understanding how the contaminated world has transformed the trajectory of evolution. It is clear that environmental contaminants are already influencing evolution on a global scale. What is not clear is what this means for our future.

\section{Abbreviations \\ $\mathrm{E}_{\mathrm{C}^{\prime}}$ epigenetic context-dependent; $\mathrm{E}_{\mathrm{g}}$ epigenetic germ- line-dependent; GWAS, genome-wide association stu- dies; HVC, higher vocal center; QTN, quantitative trait nucleotide.}

\section{Competing interests}

The authors declare they have no competing interests.

\section{Acknowledgements}

Supported by NIEHS (ES020662 and ES017538). We thank Douglas Ruden, Samuel Scarpino and Rebecca Young for helpful comments.

\section{References}

I. Diamanti-Kandarakis E, Bourguignon JP, Giudice LC, Hauser R, Prins GS, Soto AM, Zoeller RT, Gore AC: Endocrine-disrupting chemicals: an Endocrine Society scientific statement. Endocrine Rev 2009, 30:293-342.

2. Zoeller RT, Brown TR, Doan LL, Gore AC, Skakkebaek NE, Soto AM, Woodruff TJ, Vom Saal FS: Endocrine-Disrupting Chemicals and Public Health Protection: A Statement of Principles from The Endocrine Society. Endocrinology 2012, in press.

3. Vandenberg LN, Colborn T, Hayes TB, Heindel JJ, Jacobs DR, Lee DH, Shioda T, Soto AM, vom Saal FS, Welshons WV, Zoeller RT, Myers JP: Hormones and endocrine disrupting chemicals: Low-dose effects and nonmonotonic dose response. Endocrine Rev 2012, 33:378-455.

FI000 Factor 8

Evaluated by Andrea Gore 16 Aug 2012

4. Walker DM, Gore AC: Transgenerational neuroendocrine disruption of reproduction. Nature reviews. Endocrinology 201I, 7:197-207.

5. Thornton J: Pandora's Poison: Chlorine, Health and a New Environmental Strategy. Cambridge, MA: M.I.T. Press; 2000.

6. Colborn T, Dumanoski D, Myers JP: Our Stolen Future. New York: Dutton; 1996.

7. Wirgin I, Roy NK, Loftus M, Chambers RC, Franks DG, Hahn ME: Mechanistic basis of resistance to PCBs in Atlantic tomcod from the Hudson River. Science 20II, 331:1322-5.

8. Shugg TT, Abagyan R, Blumberg B, Collins TJ, Crews D, DeFur PL, Dickerson SM, Edwards TM, Gore AC, Guillette LJ, Hayes T, Heindel J], Mores AR, Patisaul HB, Tal TL, Thayer KA, Vandenberg LN, Warner J, Watson CS, vom Saal FS, Zoeller RT, O'Brien KP, Myers JP: Designing endocrine disruption out of the next generation of chemicals. Green Chemistry 2012, under revision.

9. Dobzhansky T: Genetics and the Origin of Species. New York: Columbia University Press; 1937.

10. Huxley J: Evolution: the Modern Synthesis. London: Allen and Unwin; 1942.

II. Mayr E: Systematics and the Origin of Species. Cambridge: Harvard University Press; 1942.

12. Simpson GG: Tempo and Mode in Evolution. New York: Columbia University Press; 1944.

13. Ryan MJ: Sexual selection, sensory systems, and sensory exploitation. Oxford Survey Evol Biol 1990, 7:157-96.

14. Thornton JW: Evolution of vertebrate steroid receptors from an ancestral estrogen receptor by ligand exploitation and serial genome expansions. Proc Natl Acad Sci USA 200 I, 98:567I-6.

15. Rockman MV: The QTN program and the alleles that matter for evolution: all that's gold does not glitter. Evolution 2012, 66:1-17.

FI000 Factor 12

Evaluated by Asher Cutter 28 Oct 20II, Daniel Promislow 29 Feb 2012, Norman Johnson 16 Mar 2012

16. Kuzawa C: Why evolution needs development, and medicine needs evolution. International Journal of Epidemiology 20I2, 4I:223-9.

FI000 Factor 6

Evaluated by Andrea Gore 16 Aug 2012

17. Coolen MW, Statham AL, Qu W, Campbell MJ, Henders AK, Montgomery GW, Martin NG, Clark SJ: Impact of the genome on the epigenome is manifested in DNA methylation patterns of 
imprinted regions in monozygotic and dizygotic twins. PLoS One 201 I, 6:e25590.

18. Ptak C, Petronis A: Epigenetics and complex disease: from etiology to new therapeutics. Annu Rev Pharmacol Toxicol 2008, 48:257-76.

19. Feinberg A: Phenotypic plasticity and the epigenetics of human disease. Nature 2007, 447:433-40.

20. Furrow RE, Christiansen FB, Feldman MW: Environment-sensitive epigenetics and the heritability of complex diseases. Genetics 20। I, I89: |377-87.

21. Albertson RC, Cresko W, Detrich HW, 3rd, Postlethwait JH: Evolutionary mutant models for human disease. Trends in Genetics 2009, 25:74-8I.

22. Roberts NJ, Vogelstein JT, Parmigiani G, Kinzler KW, Vogelstein B, Velculescu VE: The predictive capacity of personal genome sequencing. Sci Transl Med 20I2, 4:I33ral 58.

FI000 Factor 10

Evaluated by Andrea Gore 16 Aug 2012

23. Hoekstra HE, Coyne JA: The locus of evolution: Evo-devo and the genetics of adaptation. Evolution 2007, 6 I:995-1016.

FI000 Factor 10

Evaluated by Daniel Promislow 21 May 2007, Richard Harrison 08 Jun 2007

24. Craig LR: Defending Evo-Devo: A Response to Hoekstra and Coyne. Phil Sci 2009, 76:335-44

25. Jablonka E, Lamb M: Evolution in Four Dimensions: Genetic, Epigenetic, Behavioral, and Symbolic Variation in the History of Life. Cambridge: MIT Press; 2006

26. Crews D: Epigenetics and its implications for behavioral neuroendocrinology. Front Neuroendocrinol 2008, 29:344-57.

27. Eldredge N, Gould SJ: Punctuated equilibria: an alternative to phyletic gradualism. In Models in Paleobiology. Edited by Schopf TJM. San Francisco: Freeman, Cooper; 1972:82-II5.

28. Ablowitz R: The theory of emergence. Phil Sci 1939, 6:1-16.

FI000 Factor 10

Evaluated by Andrea Gore 16 Aug 2012

29. Goldschmidt R: The Material Basis of Evolution. New Haven: Yale University Press; 1940

30. Zeh DW, Zeh JA, Ishida Y: Transposable elements and an epigenetic basis for punctuated equilibria. BioEssays 2009, $31: 7 \mid 5-26$.

FI000 Factor 6

Evaluated by Andrea Gore 16 Aug 2012

3I. Daan S, Spoelstra K, Albrecht U, Schmutz I, Daan M, Daan B, Rienks F, Poletaeva I, Dell'Omo G, Vyssotski A, Lipp HP: Lab mice in the field: unorthodox daily activity and effects of a dysfunctional circadian clock allele. Journal Biological Rhythms 20I I, 26: I I8-29.

FI000 Factor 9

Evaluated by Matteo Carandini 25 Apr 2012, Andrea Gore 16 Aug 2012

32. Vyssotski DL: Transgenerational epigenetic compensation. Evolocus 2011, I:1-6.

33. Vyssotski DL: Transgenerational epigenetic compensation in evolution. Evolocus 2012, 1:7-12

34. Patterson HEH: Evolution and the Recognition Concept of Species. Baltimore: Johns Hopkins University Press; 1992.

35. Carson HL: Mate choice theory and the mode of selection in sexual populations. Proc Natl Acad Sci USA 2003, I00:6584-7.

36. Carson R: Silent Spring. Boston: Houghton Mifflin; 1962.

37. Mayr E: Behavior programs and evolutionary strategies. Amer Sci 1974, 62:650-9.

38. Crews D, Willingham E, Skipper JK: Endocrine disruptors: Present issues, future directions. $Q$ Rev Biol 2000, 75:243-60.

39. Markman S, Leitner S, Catchpole C, Barnsley S, Muller CT, Pascoe D, Buchanan KL: Pollutants increase song complexity and the volume of the brain area HVC in a songbird. PLOS ONE 2008, 3: el674.

40. Anway MD, Skinner MK: Epigenetic transgenerational actions of endocrine disruptors. Endocrinology 2006, I47:S43-9.

FI000 Factor 10

Evaluated by Andrea Gore 16 Aug 2012

41. Skinner MK, Anway MD, Savenkova MI, Gore AC, Crews D: Transgenerational epigenetic programming of the brain transcriptome and anxiety behavior. PLOS ONE 2008, 3(e3745) e3745.

42. Crews D, Gore AC, Hsu TS, Dangleben NL, Spinetta M, Schallert T, Anway MD, Skinner MK: Transgenerational epigenetic imprints on mate preference. Proc Natl Acad Sci USA 2007, 104:5942-6.

43. Stouder C, Paoloni-Giacobino A: Transgenerational effects of the endocrine disruptor vinclozolin on the methylation pattern of imprinted genes in the mouse sperm. Reproduction 2010 139:373-9.

FI000 Factor 6

Evaluated by Andrea Gore 16 Aug 2012

44. Crews D, Gillette R, Scarpino SV, Manikkam M, Savenkova MI, Skinner MK: Epigenetic transgenerational inheritance of altered stress response. Proc Natl Acad Sci USA 2012, in press.

45. Whitehead A: Comparative genomics in ecological physiology: toward a more nuanced understanding of acclimation and adaptation. Journal Experimental Biology 2012, 2 I 5:884-91.

46. Bateson P, Gluckman P: Plasticity, Robustness, Development and Evolution. Cambridge: Cambridge University Press; 201 I. 